\title{
Hemiparetic Knee Extensor Strength and Balance Function Are Predictors of Ambulatory Function in Subacute Stroke Patients
}

\author{
Chul Woong Hyun, $\mathrm{MD}^{1}$, Eun Young Han, $\mathrm{MD}, \mathrm{PhD}^{1}$, Sang Hee $\mathrm{Im}, \mathrm{MD}, \mathrm{PhD}^{2}$, \\ Jay Chol Choi, MD, $\mathrm{PhD}^{3}$, Bo Ryun Kim, MD, PhD ${ }^{1}$, Ho Min Yoon, $\mathrm{MD}^{1}$, Yong Ki Lee, $\mathrm{MD}^{1}$
}

${ }^{1}$ Department of Rehabilitation Medicine, Jeju National University Hospital, Jeju National University School of Medicine, Jeju; ${ }^{2}$ Department of Rehabilitation Medicine, CHA Bundang Hospital, Seongnam;

${ }^{3}$ Department of Neurology, Jeju National University Hospital, Jeju National University School of Medicine, Jeju, Korea

Objective To identify the potential predictors of ambulatory function in subacute stroke patients, and to determine the contributing factors according to gait severity.

Methods Fifty-three subacute stroke patents were enrolled. Ambulatory function was assessed by gait speed and endurance. Balance function was evaluated by the Berg Balance Scale score (BBS) and the Timed Up and Go test (TUG). The isometric muscular strengths of bilateral knee extensors and flexors were measured using an isokinetic dynamometer. Cardiovascular fitness was evaluated using an expired gas analyzer. Participants were assigned into the household ambulator group $(<0.4 \mathrm{~m} / \mathrm{s})$ or the community ambulator group $(\geq 0.4 \mathrm{~m} / \mathrm{s})$ based on gait severity. Results In the linear regression analyses of all patients, paretic knee isometric extensor strength $(\mathrm{p}=0.007)$ and BBS $(p<0.001)$ were independent predictors of gait endurance $\left(R^{2}=0.668\right)$. TUG $(p<0.001)$ and $B B S(p=0.037)$ were independent predictors of gait speed $\left(R^{2}=0.671\right)$. Paretic isometric extensor strength was a predictor of gait endurance $\left(R^{2}=0.340, p=0.008\right)$. TUG was a predictor of gait speed $\left(R^{2}=0.404, p<0.001\right)$ in the household ambulator group, whereas BBS was a predictive factor of gait endurance $\left(R^{2}=0.598, p=0.008\right)$ and speed $\left(R^{2}=0.713, p=0.006\right)$. TUG was a predictor of gait speed $\left(\mathrm{R}^{2}=0.713, \mathrm{p}=0.004\right)$ in the community ambulator group.

Conclusion Our results reveal that balance function and knee extensor isometric strength were strong predictors of ambulatory function in subacute stroke patients. However, they work differently according to gait severity. Therefore, a comprehensive functional assessment and a different therapeutic approach should be provided depending on gait severity in subacute stroke patients.

Keywords Muscle strength, Balance, Physical fitness, Gait, Stroke

Received September 19, 2014; Accepted December 31, 2014

Corresponding author: Eun Young Han

Department of Rehabilitation Medicine, Jeju National University Hospital, 15 Aran 13-gil, Jeju 690-767, Korea

Tel: +82-64-717-1672, Fax: +82-64-717-1131, E-mail: clearblue10@naver.com

(c) This is an open-access article distributed under the terms of the Creative Commons Attribution Non-Commercial License (http://creativecommons.org/ licenses/by-nc/4.0) which permits unrestricted noncommercial use, distribution, and reproduction in any medium, provided the original work is properly cited. Copyright $\odot 2015$ by Korean Academy of Rehabilitation Medicine 


\section{INTRODUCTION}

Gait impairment after stroke can lead to loss of independence and restrictions to activities of daily living, community integration, and quality of life $[1,2]$. Therefore, a major aim of stroke rehabilitation is to regain walking ability. Hemiparetic gait disturbances are associated with muscle weakness, impaired coordination and balance, decreased sensation, and spasticity of the affected limbs [3]. Many researchers have identified the basic determinants of walking capacity in stroke patients. Balance dysfunction has been suggested as an important factor leading to low ambulatory activity and further deconditioning [4]. On the other hand, lower limb muscle weakness is a major predictor of ambulatory performance [5], and in particular, knee muscle strength has been found to be strongly correlated with gait function in stroke patients [6]. Moreover, it has been demonstrated that chronic stroke patients have profoundly diminished cardiovascular fitness, which may be associated with gait deficit $[7,8]$. A previous study [9] described that $85 \%$ of patients could achieve walking ability with modified independence 6 months post-stroke, however community walking is not the same as walking in a hospital environment [10], which requires the ability to pass obstacles and to turn in the presence of many distractions. Other research has reported that $32 \%$ [11] to $47 \%$ [12] of patients were not able to walk independently in their actual community circumstances, and there are also some discrepancies between indoor and outdoor mobility.

Perry et al. [12] reported that gait velocity, a reliable and valid measure of mobility in stroke patients, is highly associated with different levels of community ambulation. They categorized gait severity according to gait velocity as the following: household ambulation referred to severe gait impairment with a velocity of $0.4 \mathrm{~m} / \mathrm{s}$; community ambulation meant moderate to mild gait impairments with a walking speed greater than $0.4 \mathrm{~m} / \mathrm{s}$ (limited community ambulation between 0.4 and $0.8 \mathrm{~m} /$ $\mathrm{s}$; full community ambulation $>0.8 \mathrm{~m} / \mathrm{s}$ ). Although gait velocity is commonly used to evaluate gait function in stroke patients, few studies have differentiated the major determinants of gait function in subacute stroke patients depending on gait severity [13]. On the other hand, gait endurance, as well as gait speed, may be important contributors to community ambulation because locomotion performance in daily life activities needs long distance walking, thus affecting their independence and participation in the community.

Therefore, the objective of this study is to determine the potential predictors of ambulatory function including gait speed and endurance in subacute stroke patients, among three main factors including balance, knee muscle strength and cardiovascular fitness, and to differentiate the major factors between household ambulators and community ambulators.

\section{MATERIALS AND METHODS}

\section{Participants}

Fifty-three patients ( 36 males and 17 females; mean age $62.6 \pm 14.3$ years) with subacute (within 3 months) stroke, who had had their first-ever cerebral stroke involving the cortical or subcortical area, were selected for this study from the Department of Physical Medicine \& Rehabilitation in Jeju National University Hospital between October 2013 and June 2014. Lesions were confirmed through magnetic resonance imaging (MRI) or computed tomography (CT). Medical history, physical and neurological examinations, and calculation of body mass index (BMI) were reviewed for all patients. The study protocol was reviewed and approved by the Institutional Review Board of our hospital. Participants were assigned the following groups: 1) suffered a first-onset primary ischemic or hemorrhagic stroke as revealed by CT or MRI; 2) had an onset of stroke within 3 months; 3 ) presented with mild to moderate hemiparesis; 4 ) were able to walk at least 3 meters with or without a walking aid and without standby assistance, and to follow instructions and communicate with the investigators. The exclusion criteria were 1) severe deficits in communication, memory, or understanding; 2) cerebellar or brainstem lesions that may affect the balance function; 3) any additional neurological or orthopedic disease causing motor deficits, such as fractures, joint degenerative changes, or clinical instability of the hip or knee joint; 4) psychiatric problems or unstable cardiorespiratory disease; and 5) contraindication of maximal exercise testing, as identified by the American College of Sports Medicine (ACSM) [14]. 
Measurements of physical performance

Ambulatory function: 10-m walk test (10MWT) and 6-minute walk distance (6MWD)

We assessed gait speed and gait endurance to evaluate subjects' ambulatory function.

For gait speed, subjects were instructed to walk $10 \mathrm{~m}$ at a comfortable but fastest pace safely possible without verbal encouragement. Time (seconds) was measured by a stopwatch. Self-selected and maximal gait velocities were calculated from the time taken to walk the 10 - $\mathrm{m}$ track. We divided all participants into 2 groups, the household ambulatory group $(<0.4 \mathrm{~m} / \mathrm{s}, \mathrm{n}=27)$ and the community ambulatory group $(\geq 0.4 \mathrm{~m} / \mathrm{s}, \mathrm{n}=26)$. To evaluate gait endurance, a 6MWD was used [15]. Subjects were instructed to walk as much as possible during the 6 minutes, while walking through a 50-m hallway marked with lines.

Balance function: Berg Balance Scale (BBS) and Timed Up and Go Test (TUG)

Balance function was evaluated using the BBS and the TUG. The BBS measures a subject's balance function while performing common functional tasks in everyday life. Each task of the BBS is rated on a 5-point scale (0-4) with a maximal score of 56 indicating good balance $[7,8]$. These tasks progress from sitting to comfortable standing, tandem standing, and single leg standing. These tasks also assess the static and dynamic balances by using usual tasks, such as reaching, standing position, and transferences.

For evaluation of TUG [16], each subject was waiting by sitting with their back against a chair (seat height, 44 $\mathrm{cm}$; depth, $45 \mathrm{~cm}$; width, $49 \mathrm{~cm}$; arm rest height, $64 \mathrm{~cm}$ ) placed at the end of a marked 3-m walkway. Subjects were instructed on the word 'go' to stand up, walk at a comfortable speed past the 3-m mark, turn around, walk back, and sit down in the chair. The time was measured in seconds.

Muscle isometric strength test: knee extensor and flexor strength

Maximal isometric strength (torques) in the bilateral knee extensors and flexors was measured with an isokinetic dynamometer, HUMAC NORM (CSMI, Stoughton, MA, USA) while subjects were seated on a speciallydesigned chair with hip angles at approximately $85^{\circ}$ [17].
The distal shin pad of the dynamometer was attached 2-3 cm proximal to the lateral malleolus using a strap. To minimize inappropriate trunk movements during thigh muscle contractions, straps were applied across the chest, pelvis, and mid-thigh. The alignment between the dynamometer rotational axis and the knee joint rotational axis (lateral femoral epicondyle) was adjusted at the beginning of each trial.

Gravity effect torque was recorded on each subject. This was used to correct torque measurements during all tests. Participants were asked to grasp sidebars during the testing procedure. The length of the moving arm measured from the lateral femoral epicondyle to the center of the force transducer at the shin was kept constant. Data were obtained from digitized signals. After a structured warmup, with the knee joint fixed at an angle of $60^{\circ}$ of flexion for maximal isometric force generation [18], subjects were asked to perform maximal voluntary contractions until torque did not further increase by greater than $5 \%$, with 3 attempts in succession. Knee flexion and extension were performed as discrete movements in a single direction (non-reciprocal). Each contraction lasted 4 to 5 seconds separated by 2 minutes of rest. During each attempt, we loudly encouraged subjects to achieve maximal performance. After 5 minutes of rest, the same procedure was performed with the other lower limb.

Symptom-limited exercise stress test: treadmill test and bicycle ergometer test

Subjects underwent a symptom-limited exercise stress test using a calibrated motorized treadmill, T-2100 (GE Healthcare Inc., Chalfont St. Giles, UK) or a bicycle ergometer, Ergoselect 600K (Ergoline GmbH, Lindenstraße, Germany). Peak exercise cardiovascular responses were measured. Exercise tests were conducted in the presence of one physiatrist and one physical therapist. To select the targeted safe and fastest walking velocity, the zero-incline treadmill test was started at $0.5 \mathrm{mph}$ and slowly advanced in $0.1 \mathrm{mph}$ increments. Patients were allowed 15 minutes of seated rest [19]. For constant velocity and graded treadmill stress testing, patients walked on the treadmill without an incline during the initial 2 minutes, followed by 2 minutes at a $4 \%$ incline, and a $2 \%$ increase per 2 minutes thereafter. Handrail support was minimally allowed. A gait belt support and supervised observation were provided as safety measures. The exercise test was terminated 
on the patient's demand or in the presence of gait instability or a sign of cardiovascular decompensation.

For patients who could not conduct the treadmill stress test, an ergometer test was applied [20]. The bicycle ergometer test was performed at a rate of 50-60 revolutions per minute (rpm). Workload was started at $10 \mathrm{~W}$ during 2 minutes, and increased by $5 \mathrm{~W}$ per 2 minutes. Guidelines provided by the ACSM were used to determine when the test should be terminated prematurely [21].

$\mathrm{VO}_{2}$ max was considered when at least two of the following three criteria for maximal effort were fulfilled: 1 ) a respiratory exchange ratio $\geq 1.0 ; 2)$ a plateau in $\mathrm{VO}_{2}(<150$ $\mathrm{mL} / \mathrm{min}$ ) with an increase in exercise intensity; 3) volitional fatigue (decline in cycling rate $<30 \mathrm{rpm}$ ) [21,22]. If the parameter did not fulfill the criteria, the peak values of the parameter were adopted. Peak oxygen consumption $\left(\mathrm{VO}_{2}\right.$ peak), metabolic equivalent, resting/peak heart rate (RHR/PHR), resting/peak blood pressure (RBP/ PBP), peak rate pressure product, exercise duration, respiratory exchange ratio, estimated anaerobic threshold, submaximal rate pressure product, and submaximal rate of perceived exertion-Borg Scale, from 6 to 20-were determined. PHR achieved at the end of the test was expressed as a percentage (\%) of the age-predicted HR maximum $[\mathrm{PHR} /(220$ - age $) \times 100][21]$.

\section{Statistical analysis}

Descriptive statistics were used to calculate the mean and standard deviation. A Student t-test was used to compare baseline values such as functional parameters depending on gender, stroke type, and lesion side between the two groups. Pearson correlation analysis was used to assess the relationship of physical performance with ambulatory function. A multivariate linear regression analysis using a backward selection model was applied to determine which physical performances were significant predictors of ambulatory function. All statistical analyses were performed using the SPSS statistical package ver. 12.0 (SPSS Inc., Chicago, IL, USA). A statistically significant difference was considered with a p-value of less than 0.05 .

\section{RESULTS}

\section{Demographic and clinical characteristics}

A total of 53 patients (average age, $62.6 \pm 14.3$ years; 36
Table 1. General characteristics, neurological deficits, gait function, cardiovascular fitness, and knee strength of all stroke patients $(n=53)$

\begin{tabular}{lc}
\hline \multicolumn{1}{c}{ Characteristic } & Value \\
\hline Age (yr) & $62.6 \pm 14.3$ \\
Gender (male:female) & $36: 17$ \\
\hline Post-stroke duration (day) & $39.9 \pm 35.0$ \\
\hline BMI (kg/m ${ }^{2}$ ) & $23.9 \pm 3.2$ \\
\hline Stroke type (ischemic:hemorrhagic) & $40: 13$ \\
\hline Lesion side (left:right) & $23: 30$ \\
\hline Function & \\
\hline BBS score & $36.1 \pm 15.2$ \\
\hline TUG (s) & $34.2 \pm 31.6$ \\
Gait function & \\
\hline 10MWT velocity (m/s) & $0.6 \pm 0.4$ \\
\hline 6MWD (m) & $175.1 \pm 123.7$ \\
\hline Cardiovascular fitness & $15.6 \pm 5.5$ \\
\hline VO ${ }_{2}$ peak (mL/kg/min) & \\
\hline Knee extensor strength (Nm) & $51.9 \pm 37.4$ \\
\hline Paretic leg & $75.2 \pm 36.2$ \\
\hline Nonparetic leg & $34.8 \pm 25.0$ \\
\hline Knee flexor strength (Nm) & $51.3 \pm 23.6$ \\
\hline Paretic leg & Nonparetic leg
\end{tabular}

Values represent the mean \pm standard deviation or number. BMI, body mass index; BBS, Berg Balance Scale; TUG, Timed Up and Go test; 10MWT, 10-meter walk test; $6 \mathrm{MWD}$, 6-minute walk distance; $\mathrm{VO}_{2}$, oxygen consumption.

males and 17 females) with subacute hemiparetic stroke were enrolled. Demographic characteristics of participants are summarized in Table 1. Demographic characteristics including gender, age, post-stroke duration, BMI, stroke type, and lesion side failed to show a significant difference between the household ambulator group and the community ambulator group ( $p>0.05)$ (Table 2$)$.

Functions of gait, balance, knee strength, and cardiovascular fitness

Clinical characteristics including gait, balance, knee strength, and cardiovascular fitness functions are listed in Table 1. All clinical values showed significant $(p<0.05)$ differences between the household ambulator group and the community ambulator group (Table 2 ). In 10MWT, 
Table 2. Comparison of general characteristics, neurological deficits, gait function, cardiovascular fitness, and knee strength in the household ambulator and community ambulator groups

\begin{tabular}{|c|c|c|c|}
\hline Variable & $\begin{array}{l}\text { Household ambulator } \\
(<0.4 \mathrm{~m} / \mathrm{s}, \mathrm{n}=27)\end{array}$ & $\begin{array}{c}\text { Community ambulator } \\
(\geq 0.4 \mathrm{~m} / \mathrm{s}, \mathrm{n}=26)\end{array}$ & p-value \\
\hline Age (yr) & $64.3 \pm 15.4$ & $60.7 \pm 13.1$ & 0.36 \\
\hline Gender (male:female) & 10:17 & $7: 19$ & 0.56 \\
\hline Post-stroke duration (day) & $44.5 \pm 35.0$ & $35.4 \pm 35.2$ & 0.35 \\
\hline BMI $\left(\mathrm{kg} / \mathrm{m}^{2}\right)$ & $23.3 \pm 2.6$ & $24.6 \pm 3.7$ & 0.17 \\
\hline Stroke type (ischemic:hemorrhagic) & $21: 6$ & $17: 7$ & 0.78 \\
\hline Lesion side (left:right) & $10: 17$ & $13: 13$ & 0.41 \\
\hline \multicolumn{4}{|l|}{ Balance function } \\
\hline BBS score & $25.0 \pm 12.6$ & $47.6 \pm 6.8$ & $<0.001^{* *}$ \\
\hline TUG $(s)$ & $53.5 \pm 34.5$ & $14.2 \pm 5.3$ & $<0.001^{* *}$ \\
\hline \multicolumn{4}{|l|}{ Gait function } \\
\hline 10MWT velocity $(\mathrm{m} / \mathrm{s})$ & $0.3 \pm 0.2$ & $0.9 \pm 0.3$ & $<0.001^{* *}$ \\
\hline 6MWD (m) & $80.6 \pm 59.4$ & $273.3 \pm 92.1$ & $<0.001^{* *}$ \\
\hline \multicolumn{4}{|l|}{ Cardiovascular fitness } \\
\hline $\mathrm{VO}_{2}$ peak $(\mathrm{mL} / \mathrm{kg} / \mathrm{min})$ & $13.1 \pm 3.4$ & $18.1 \pm 6.0$ & $<0.001^{* *}$ \\
\hline \multicolumn{4}{|l|}{ Knee extensor strength (Nm) } \\
\hline Paretic leg & $31.7 \pm 23.9$ & $72.8 \pm 37.7$ & $<0.001^{* *}$ \\
\hline Nonparetic leg & $62.3 \pm 24.4$ & $88.5 \pm 41.8$ & $0.01^{*}$ \\
\hline \multicolumn{4}{|l|}{ Knee flexor strength (Nm) } \\
\hline Paretic leg & $22.0 \pm 13.6$ & $48.1 \pm 27.4$ & $<0.001^{* *}$ \\
\hline Nonparetic leg & $42.6 \pm 18.0$ & $60.4 \pm 25.6$ & $0.01^{*}$ \\
\hline
\end{tabular}

Values represent the mean \pm standard deviation or number.

BMI, body mass index; BBS, Berg Balance Scale; TUG, Timed Up and Go test; 10MWT, 10-meter walk test; 6MWD, 6-minute walk distance; $\mathrm{VO}_{2}$, oxygen consumption.

${ }^{*} \mathrm{p}<0.05,{ }^{* *} \mathrm{p}<0.001$.

the mean velocity of the household ambulator group was $0.3 \pm 0.2 \mathrm{~m} / \mathrm{s}$ and that of the community ambulator group was $0.9 \pm 0.3 \mathrm{~m} / \mathrm{s}$. In $6 \mathrm{MWD}$, the mean value of the household ambulator group was $80.6 \pm 59.4 \mathrm{~m}$ and that of the community ambulator group was $273.3 \pm 92.1 \mathrm{~m}$. In BBS, the mean score of the household ambulator group was $25.0 \pm 12.6$ and that of the community ambulator group was $47.6 \pm 6.8$. In TUG, the mean time of the household ambulator group was $53.5 \pm 34.5$ seconds and that of the community ambulator group was $14.2 \pm 5.3$ seconds. In cardiovascular fitness, the mean $\mathrm{VO}_{2}$ peak of the household ambulator group was $13.1 \pm 3.4 \mathrm{~mL} / \mathrm{kg} / \mathrm{min}$ and that of the community ambulator group was $18.1 \pm 6.0 \mathrm{~mL} / \mathrm{kg} /$ $\min$.

The mean torques of the paretic and non-paretic quadriceps of the household ambulator group were
$31.7 \pm 23.9 \mathrm{Nm}$ and $62.3 \pm 24.4 \mathrm{Nm}$, respectively. Those of the community ambulator group were $72.8 \pm 37.7 \mathrm{Nm}$ and $88.5 \pm 27.4 \mathrm{Nm}$, respectively. The mean torques of the paretic and non-paretic hamstrings of the household ambulator group were $22.0 \pm 13.6 \mathrm{Nm}$ and $42.6 \pm 18.0 \mathrm{Nm}$, respectively. Those of the community ambulator group were $48.1 \pm 27.4 \mathrm{Nm}$ and $60.4 \pm 25.6 \mathrm{Nm}$, respectively.

Relationship between physical performance parameters and ambulatory function

In all participants, balance function (TUG, $r=-0.637$ ), cardiovascular fitness $\left(\mathrm{VO}_{2}\right.$ peak, $\left.\mathrm{r}=0.420\right)$, bilateral knee extensor (paretic, $r=0.610$; nonparetic, $r=0.424$ ), and flexor (paretic, $r=0.593$; nonparetic, $r=0.357$ ) strengths showed a significant $(\mathrm{p}<0.01)$ correlation with gait endurance (6MWD). Balance function (BBS, $r=0.802$; TUG, $r=$ 
Table 3. Backward linear regression models of 6MWD for all subjects, the household ambulator group, and the community ambulator group

\begin{tabular}{lcc}
\hline \multicolumn{1}{c}{ Variable } & Adjusted R $^{2}$ & p-value \\
\hline All subjects & & \\
\hline BBS score & 0.668 & $<0.001^{* *}$ \\
\hline $\begin{array}{l}\text { Paretic knee extensor strength } \\
\text { Household ambulator }\end{array}$ & 0.668 & $0.007^{*}$ \\
$\begin{array}{l}\text { Paretic knee extensor strength } \\
\text { Community ambulator }\end{array}$ & 0.340 & $0.008^{*}$ \\
\hline \begin{tabular}{l} 
BBS score \\
\hline
\end{tabular} & 0.598 & $0.008^{*}$ \\
\hline
\end{tabular}

6MWD, 6-minute walk distance; BBS, Berg Balance Scale. ${ }^{*} \mathrm{p}<0.05,{ }^{* *} \mathrm{p}<0.001$.

-0.712), cardiovascular fitness $\left(\mathrm{VO}_{2}\right.$ peak, $\left.\mathrm{r}=0.460\right)$, bilateral knee extensor strengths (paretic, $\mathrm{r}=0.550$; nonparetic, $\mathrm{r}=0.329)$, and paretic knee flexor strengths $(\mathrm{r}=0.510)$ were significantly $(\mathrm{p}<0.01)$ correlated with gait speed (10MWT velocity).

In the backward linear regression analyses, paretic isometric extensor strength $(\mathrm{p}=0.007)$ and BBS $(\mathrm{p}<0.001)$ were independent predictors of gait endurance (adjusted $\mathrm{R}^{2}=0.668$ ) in all patients. Paretic isometric extensor strength was a predictor of gait endurance in the household ambulator group (adjusted $\mathrm{R}^{2}=0.340$ ), while the BBS score was a predictor of gait endurance in the community ambulator group (adjusted $\mathrm{R}^{2}=0.598$ ) (Table 3 ).

The TUG and BBS scores $(\mathrm{p}<0.001)$ were independent predictors of gait speed (adjusted $\mathrm{R}^{2}=0.668$ ) in all patients. TUG was a predictor of gait speed in the household ambulator group (adjusted $\mathrm{R}^{2}=0.340$ ), whereas TUG and BBS were independent predictors of gait speed in the community ambulator group (adjusted $\mathrm{R}^{2}=0.598$ ) (Table 4).

\section{DISCUSSION}

Our results demonstrate that hemiparetic knee extensor strength is a predictor of gait endurance and that balance function is also a major determinant of gait speed and endurance in subacute stroke patients. Although several studies have reported a close relationship between balance function and gait performance, few studies have researched the effect of knee extensor strength on ambulatory function $[23,24]$. Most studies have assessed gait function using gait speed or short distant walking
Table 4. Backward linear regression models of 10MWT velocity for all subjects, the household ambulator group, and the community ambulator group

\begin{tabular}{lcc}
\hline \multicolumn{1}{c}{ Variable } & Adjusted $\mathbf{R}^{2}$ & p-value \\
\hline All subjects & & \\
$\quad$ TUG & 0.671 & $<0.001^{* *}$ \\
$\quad$ BBS score & 0.671 & $0.037^{*}$ \\
Household ambulator & & \\
$\quad$ TUG & 0.404 & $<0.001^{* *}$ \\
$\begin{array}{l}\text { Community ambulator } \\
\text { TUG }\end{array}$ & 0.713 & $0.004^{*}$ \\
BBS score & 0.713 & $0.006^{*}$ \\
\hline
\end{tabular}

10MWT, 10-meter walk test; BBS, Berg Balance Scale; TUG, Timed Up and Go test.

${ }^{*} \mathrm{p}<0.05,{ }^{* *} \mathrm{p}<0.001$.

only. Here, we measured gait endurance and speed, and performed subgroup analysis depending on gait severity. Our results indicate that hemiparetic knee extensor strength, as well as balance, had a significant correlation with gait endurance. However, only balance function had a significant influence on gait speed in subacute stroke patients. This finding was consistent with a previous study that reported the close correlation between knee extensor strength of the paretic leg and BBS and 6MWT [25]. Most stroke patients had lower limb muscle weakness, particularly the quadriceps and hamstring [26], which induced several kinematic gait problems. Knee extensor may support knee stability in the stance phase and maintain the sufficient stance phase in the paretic limb, therefore enabling the non-paretic limb to proceed in a swing phase during long distance walking. If paretic muscle strength is decreased, muscle fatigue increases, thus affecting overall gait endurance. Therefore, paretic knee extensor strength was important during walking in stroke patients. We found that paretic knee extensor strength acted more significantly in gait endurance in the household ambulator group.

Furthermore, there has been little research reporting the relative ratio of paretic and nonparetic leg isometric strength according to gait severity. In our present study, the mean paretic and nonparetic muscle isometric strength showed significant differences according to gait severity and the mean paretic knee extensor and flexor torques of the household ambulator group were approximately $50.9 \%$ and $51.6 \%$, compared with those of the 
nonparetic leg, while the mean paretic knee extensor and flexor torques of the community ambulator group were approximately $82.2 \%$ and $79.6 \%$, compared with those of the nonparetic leg. Therefore, strengthening exercise of the paretic leg muscles in subacute stroke patients with severe gait deficit should be emphasized. Further studies are merited in order to determine adequate isometric strength for community ambulation.

The BBS score, an appropriate and validated tool that measures balance function, is widely used to assess basic walking balance [27]. However, BBS is an indicator of falling risk in the elderly. In addition, BBS does not include the walking balance task. Furthermore, BBS has a limitation of ceiling effect that cannot represent the walking function of community ambulators. Our study reveals that the BBS score was a strong predictor of gait endurance and speed, especially in the community ambulator group. In our study, the community ambulator group had a mean velocity of $0.9 \pm 0.3 \mathrm{~m} / \mathrm{s}$, a mean $6 \mathrm{MWD}$ of $273.3 \pm 92.1 \mathrm{~m}$, and a mean BBS score of $47.6 \pm 6.8$. The velocity and distance were consistent with full community walking velocity and gait endurance published in a previous study [28]. On the contrary, the BBS score of our participants may not have reached the highest score of full community level that had ceiling effects. One research study reported that after 3 months, gait velocity did not change, but the BBS score was improved significantly [29]. Therefore, the BBS score may predict gait function of community ambulators during the subacute phase after stroke. Future research with long-term follow-up is warranted to confirm these results.

The TUG tool indicates similar levels of content validity to that of the BBS [27]. However, compared with the BBS scale, TUG involves complex functional movements such as transfers and turning in addition to walking. It was speculated that these additional components of mobility performance could provide greater discrimination when predicting gait speed and dynamic balance in subacute stroke patients $[30,31]$. Our data indicate that TUG was a strong predictor of gait velocity in subacute stroke patients, irrespective of ambulatory function. However, BBS could not predict gait speed of household ambulators with subacute stroke. Therefore, we cautiously recommend that balance function of subacute stroke patients should be evaluated by both the BBS and TUG score for predicting their gait function.
Unexpectedly, the $\mathrm{VO}_{2}$ peak was not a predictor of gait function in our study, although it was related to gait function. Pang et al. [20] reported similar data with respect to the fact that cardiovascular fitness was not related to gait function in stroke patients. However, another study [32] mentioned that the $\mathrm{VO}_{2}$ peak was related to $6 \mathrm{MWD}$, especially in stroke patients with milder deficits. One explanation for such discrepancy was that the exam time was too early to measure the exact maximal $\mathrm{VO}_{2}$. We previously performed ETT using a treadmill at approximately 1 month after stroke onset [33], and our patients in the community ambulator group assessed their cardiorespiratory function at post-onset $35.4 \pm 35.2$ days. However, there has been no report regarding the exact time to conduct the exercise tolerance test using an ergometer and to acquire data of the $\mathrm{VO}_{2}$ peak in the household stroke patients in the subacute phase. Thus, further research is warranted to identify a reliable test time. Another explanation was that incongruent equipment such as the treadmill and bicycle ergometer were used to determine $\mathrm{VO}_{2}$ peak depending on gait severity. Although the exercise tolerance test using a treadmill is the most adequate method to evaluate cardiovascular fitness, it is not applicable to all patients due to different balance and gait dysfunction. As Pang et al. [20] reported, a bicycle ergometer would underestimate peak cardiovascular fitness compared with the treadmill. The incongruent equipment would act as a confounding factor in this study. Therefore, it will be necessary to analyze the results according to each device in future large-scale studies.

There are several limitations in our study. Firstly, the sample size in this study was relatively small, so we could not perform subgroup analysis according to stroke location. Although we did not include the patients with stroke location such as brain stem or cerebellum that would affect the balance and gait function, further study should assess their effects on the balance and gait function. Secondly, we focused on knee muscle strength rather than hip and ankle muscle strength, because we assumed that knee muscle strength has been strongly correlated with gait function in stroke patients. Nevertheless, the various muscle factors may be considered for further studies. Finally, our study was a cross-sectional study about physical performance and we did not confirm the changes in gait parameters over time and, we could not assure the appropriate time for measuring the exercise tolerance 
test of subacute stroke patients. Therefore, further studies should be conducted on the longitudinal assessment of physical performance.

In conclusion, our results show that balance function and knee extensor isometric strength were major contributors to ambulatory functions in subacute stroke patients. In subacute household ambulators, knee extensor isometric muscular strength was a predictor of gait endurance, and balance function was a major predictor of gait speed. In subacute community ambulators, balance function was a major predictor of gait endurance and speed. Therefore, a comprehensive functional assessment and a different therapeutic approach should be provided depending on gait severity in subacute stroke patients.

\section{CONFLICT OF INTEREST}

No potential conflict of interest relevant to this article was reported.

\section{ACKNOWLEDGMENTS}

This research was supported by the 2014 scientific promotion program funded by Jeju National University.

\section{REFERENCES}

1. Weerdesteyn V, de Niet M, van Duijnhoven HJ, Geurts AC. Falls in individuals with stroke. J Rehabil Res Dev 2008;45:1195-213.

2. de Oliveira CB, de Medeiros IR, Frota NA, Greters ME, Conforto AB. Balance control in hemiparetic stroke patients: main tools for evaluation. J Rehabil Res Dev 2008;45:1215-26.

3. Goldie PA, Matyas TA, Evans OM. Deficit and change in gait velocity during rehabilitation after stroke. Arch Phys Med Rehabil 1996;77:1074-82.

4. Michael KM, Allen JK, Macko RF. Reduced ambulatory activity after stroke: the role of balance, gait, and cardiovascular fitness. Arch Phys Med Rehabil 2005;86: 1552-6.

5. Bohannon RW. Muscle strength and muscle training after stroke. J Rehabil Med 2007;39:14-20.

6. Suzuki K, Imada G, Iwaya T, Handa T, Kurogo H. Determinants and predictors of the maximum walking speed during computer-assisted gait training in hemiparetic stroke patients. Arch Phys Med Rehabil 1999; 80:179-82.

7. Steffen TM, Hacker TA, Mollinger L. Age- and genderrelated test performance in community-dwelling elderly people: six-minute walk test, berg balance scale, timed up \& go test, and gait speeds. Phys Ther 2002; 82:128-37.

8. Smith PS, Hembree JA, Thompson ME. Berg balance scale and functional reach: determining the best clinical tool for individuals post acute stroke. Clin Rehabil 2004;18:811-8.

9. Wade DT, Hewer RL. Functional abilities after stroke: measurement, natural history and prognosis. J Neurol Neurosurg Psychiatry 1987;50:177-82.

10. Lord SE, Rochester L, Weatherall M, McPherson KM, McNaughton HK. The effect of environment and task on gait parameters after stroke: a randomized comparison of measurement conditions. Arch Phys Med Rehabil 2006;87:967-73.

11. Lord SE, McPherson K, McNaughton HK, Rochester L, Weatherall M. Community ambulation after stroke: how important and obtainable is it and what measures appear predictive? Arch Phys Med Rehabil 2004; 85:234-9.

12. Perry J, Garrett M, Gronley JK, Mulroy SJ. Classification of walking handicap in the stroke population. Stroke 1995;26:982-9.

13. Bowden MG, Embry AE, Gregory CM. Physical therapy adjuvants to promote optimization of walking recovery after stroke. Stroke Res Treat 2011;2011:601416.

14. Kelly JO, Kilbreath SL, Davis GM, Zeman B, Raymond J. Cardiorespiratory fitness and walking ability in subacute stroke patients. Arch Phys Med Rehabil 2003;84: 1780-5.

15. Wade DT. Measurement in neurological rehabilitation. Curr Opin Neurol Neurosurg 1992;5:682-6.

16. Podsiadlo D, Richardson S. The timed "Up \& Go": a test of basic functional mobility for frail elderly persons. J Am Geriatr Soc 1991;39:142-8.

17. Maffiuletti NA, Bizzini M, Desbrosses K, Babault N, Munzinger U. Reliability of knee extension and flexion measurements using the Con-Trex isokinetic dynamometer. Clin Physiol Funct Imaging 2007;27:346-53.

18. Thorstensson A, Karlsson J. Fatiguability and fibre composition of human skeletal muscle. Acta Physiol 
Scand 1976;98:318-22.

19. Macko RF, Katzel LI, Yataco A, Tretter LD, DeSouza CA, Dengel DR, et al. Low-velocity graded treadmill stress testing in hemiparetic stroke patients. Stroke 1997;28:988-92.

20. Pang MY, Eng JJ, Dawson AS. Relationship between ambulatory capacity and cardiorespiratory fitness in chronic stroke: influence of stroke-specific impairments. Chest 2005;127:495-501.

21. Thompson WR, Gordon NF, Pescatello LS. ACSM's guidelines for exercise testing and prescription. 8th ed. Philadelphia: Lippincott Williams \& Wilkins; 2010.

22. Howley ET, Bassett DR Jr, Welch HG. Criteria for maximal oxygen uptake: review and commentary. Med Sci Sports Exerc 1995;27:1292-301.

23. Bohannon RW, Walsh S. Nature, reliability, and predictive value of muscle performance measures in patients with hemiparesis following stroke. Arch Phys Med Rehabil 1992;73:721-5.

24. Hsu AL, Tang PF, Jan MH. Analysis of impairments influencing gait velocity and asymmetry of hemiplegic patients after mild to moderate stroke. Arch Phys Med Rehabil 2003;84:1185-93.

25. Gerrits KH, Beltman MJ, Koppe PA, Konijnenbelt H, Elich PD, de Haan A, et al. Isometric muscle function of knee extensors and the relation with functional performance in patients with stroke. Arch Phys Med Rehabil 2009;90:480-7.
26. Moseley A, Wales A, Herbert R, Schurr K, Moore S. Observation and analysis of hemiplegic gait: stance phase. Aust J Physiother 1993;39:259-67.

27. Pollock C, Eng J, Garland S. Clinical measurement of walking balance in people post stroke: a systematic review. Clin Rehabil 2011;25:693-708.

28. Combs SA, Van Puymbroeck M, Altenburger PA, Miller KK, Dierks TA, Schmid AA. Is walking faster or walking farther more important to persons with chronic stroke? Disabil Rehabil 2013;35:860-7.

29. Lee JH, Kim SB, Lee KW, Lee JY. The effect of prolonged inpatient rehabilitation therapy in subacute stroke patients. Ann Rehabil Med 2012;36:16-21.

30. Fulk GD, Reynolds C, Mondal S, Deutsch JE. Predicting home and community walking activity in people with stroke. Arch Phys Med Rehabil 2010;91:1582-6.

31. Mackintosh SF, Hill K, Dodd KJ, Goldie P, Culham E. Falls and injury prevention should be part of every stroke rehabilitation plan. Clin Rehabil 2005;19:441-51.

32. Baert I, Vanlandewijck Y, Feys H, Vanhees L, Beyens H, Daly D. Determinants of cardiorespiratory fitness at 3, 6 and 12 months poststroke. Disabil Rehabil 2012;34: 1835-42.

33. Kim BR, Han EY, Joo SJ, Kim SY, Yoon HM. Cardiovascular fitness as a predictor of functional recovery in subacute stroke patients. Disabil Rehabil 2014;36:22731. 